\title{
The GENAHTO Project (Gender and Alcohol's Harm to Others): Design and Methods for a Multinational Study of Alcohol's Harm to Persons Other than the Drinker
}

\author{
Sharon C. Wilsnack ${ }^{1}$, Thomas K. Greenfield ${ }^{2}$, Kim Bloomfield ${ }^{3}$ \\ ${ }^{1}$ University of North Dakota School of Medicine and Health Sciences, Grand Forks, North Dakota, USA \\ ${ }^{2}$ Alcohol Research Group/Public Health Institute, Emeryville, California, USA \\ ${ }^{3}$ Centre for Alcohol and Drug Research, Aarhus University, Copenhagen, Denmark
}

\begin{abstract}
Aims: Most alcohol research has focused on how drinking harms the drinker. Research on alcohol's harms to others (AHTO) has studied primarily single or small groups of countries. This article describes the methodology of a new multinational studyGender and Alcohol's Harm to Others (GENAHTO) — of how social and cultural contexts are related to AHTO, from the perspectives of both perpetrators and victims.

Design: The GENAHTO Project uses surveys in 21 countries that provide data from drinkers who report causing harms to others, and surveys in 16 countries that provide data from victims of AHTO. The countries surveyed vary widely in alcohol policies, drinking cultures, gender-role definitions, and socioeconomic conditions.

Participants: More than 140,000 men and women, aged 15-84, participated in the surveys.

Measures: Individual-level measures include demographics, alcohol use patterns, and alcohol-related harms. Regional- and societal-level measures include socioeconomic conditions, drinking patterns, alcohol policies, gender inequality, and income inequality.
\end{abstract}

Findings: The project seeks to identify characteristics of AHTO victims and perpetrators; within-country regional differences in AHTO; and associations between national alcohol polices and individual and regional levels of AHTO.

Conclusions: GENAHTO is the first project to assess AHTO in diverse societies. Its findings can inform policies to abate AHTO in varying cultural contexts.

Research on alcohol use and alcohol-related problems has focused largely on how drinking harms the drinker. Prior research on alcohol's harm to other people has studied mainly drink-driving (Berning, Compton, \& Wochinger, 2015; Hingson \& Winter, 2003; Kelley-Baker, Lacey, Voas, Romano, \& Yao, 2013), fetal alcohol effects (Popova \& Chambers, 2013, 2014), and intimate partner violence (Flynn \& Graham, 2010; Graham, Bernards, Munné, \& Wilsnack, 2008), neglecting broader harms to others' health, quality of life, living conditions, and resources. Research in Australia (Laslett et al., 2010, 2011) and New Zealand (Casswell, Harding, You, \& Huckle, 2011) suggests that broader harms to others may double the costs of alcohol use/misuse. Concerns about alcohol's harms to others (AHTO) are similar to concerns about effects of second- hand smoke, which have had substantial impact on tobacco control policy (Giesbrecht, Cukier, \& Steeves, 2010; Raupach, Schäfer, Konstantinides, \& Andreas, 2006; U.S. Department of Health and Human Services, 2006). The 2010 World Health Organization (WHO) global strategy on alcohol (WHO, 2011) stated that protecting people from exposure to AHTO is essential in alcohol policies.

Most research on AHTO to date has studied only individual countries (e.g., Casswell et al., 2011; Greenfield, KarrikerJaffe, Kaplan, Kerr, \& Wilsnack, 2015; Laslett et al., 2011) or small groups of countries (Lund et al., 2015), focusing primarily on characteristics of individuals harmed by others' drinking. For more effective interventions and policies to reduce AHTO, it is essential to understand also how social

Correspondence: Sharon C. Wilsnack, Ph.D., Department of Psychiatry and Behavioral Science, UND School of Medicine and Health Sciences, 1301 North Columbia Road Stop 9037, Grand Forks, North Dakota 58202-9037, USA. Phone: 701-777-3065, Email: sharon.wilsnack@und.edu

Financial support: The preparation of this manuscript was supported by Grant No. R01 AA023870 from the National Institute on Alcohol Abuse and Alcoholism (NIAAA)/National Institutes of Health (NIH), for which the authors are Multiple Principal Investigators. Partial support also came from Grant No. P50 AA005595. The content is solely the responsibility of the authors and does not necessarily express the official positions of NIAAA or NIH.

Declaration of interest: The authors declare that they have no competing financial or other interests.

Keywords: alcohol, harms, others, multinational, policy 
and cultural contexts are related to the risks, types, and severity of AHTO. The present article provides an overview of the GENAHTO Project, a multinational study of individual and sociocultural correlates of AHTO. The article summarizes the history of the emerging AHTO "paradigm"; the study design of the GENAHTO Project, including its conceptual model, major goals, and data collection and data analysis methods; and its potential implications for approaches to prevention, intervention, and policy.

\section{History}

\section{Early studies}

One of the first studies of how alcohol harms persons other than the drinker, by sociologist Kaye Fillmore (Fillmore, 1985), focused on the "social victims of drinking" in a Western U.S. city. More recent data from the U.S. National Alcohol Survey confirmed Fillmore's findings that women report more family and financial harms from others' drinking, whereas men report more physical assaults from other drinkers (e.g., Greenfield et al., 2009). Other studies using U.S. National Alcohol Survey data have found that neighborhood disadvantage and gender interact in predicting rates of family-related and stranger-violence-related AHTO (Karriker-Jaffe \& Greenfield, 2014), and that persons experiencing AHTO are more likely to favor stronger alcohol policies (Greenfield et al., 2014).

Surveys conducted in 2008 in Australia (Ferris, Laslett, Livingston, Room, \& Wilkinson, 2011; Laslett et al., 2010; Mugavin, Livingston, \& Laslett, 2014) and New Zealand (Casswell et al., 2011) have now led to a diversity of national studies of harm from others' drinking, in Canada (LewisLaietmark et al., 2017), Ireland (Hope, 2008), Denmark (Seid, Grittner, Greenfield, \& Bloomfield, 2015), and Northern Europe (Moan et al., 2015; Ramstedt et al., 2015).

\section{The GENACIS Project}

Two large multinational projects collected general population survey data that are re-analyzed in the GENAHTO Project. GENACIS (Gender, Alcohol, and Culture: An International Study) studied cultural and gender-related influences on the alcohol use of women and men. GENACIS included comparable general population surveys conducted between 1997 and 2007 in 38 countries on six continents (Wilsnack, Wilsnack, Kristjanson, Vogeltanz-Holm, \& Gmel, 2009; Wilsnack, 2012). The deidentified GENACIS data sets were edited, formatted, and archived at the Addiction Switzerland Research Institute in Lausanne (and subsequently also at the Centre for Alcohol Policy Research [CAPR] at La Trobe University, Melbourne, Australia). Funding sources included the European Union, WHO, the Pan American Health Organization, the U.S. National Institute on Alcohol Abuse and Alcoholism (NIAAA), and individual country sources.

The standard GENACIS questionnaire focused mainly on drinking consequences for the drinker but also included questions about harms that drinking respondents reported causing for other persons, as well as questions about getting in fights and about aggression toward a spouse/partner while drinking. The GENAHTO Project uses GENACIS data to identify characteristics of persons whose drinking causes harm to other persons.

\section{The WHO-Thai Health Project}

In 2011, a project funded jointly by WHO and the ThaiHealth Promotion Foundation (WHO-TH) conducted population surveys in seven lower- and middle-income countries - Chile, India, Lao People's Democratic Republic, Nigeria, Sri Lanka, Thailand, and Vietnam-using a common protocol and questionnaire (Callinan et al., 2016; WHO, 2012). The WHO-TH Project also incorporated the Australia (Laslett et al., 2010) and New Zealand (Casswell et al., 2011) AHTO surveys mentioned above. The project used two versions of a standard questionnaire. Both versions included 13 core questions about experiencing specific harms from strangers' drinking or from known persons' drinking (the "Brief Assessment of Harms," available on request from the authors). Version 1 also included follow-up questions about estimated financial costs of the harms experienced; Version 2 did not ask for cost estimates but included additional questions about drinking contexts, the respondent's own drinking and its perceived consequences, attitudes toward drinking and intoxication in varying social settings, and all questions from the Alcohol Use Disorders Identification Test (Saunders, Aasland, Babor, De la Fuente, $\&$ Grant, 1993). Many of these questions were taken or adapted from the standard GENACIS questionnaire.

Funding from WHO and the Australian National Health and Medical Research Council has supported the costs of archiving the WHO-TH data sets at the La Trobe University CAPR, in Melbourne, Australia. Care was taken to edit, format, and merge the WHO-TH data sets in the same manner as the GENACIS data sets, so that the two data archives are as comparable as possible.

\section{Other AHTO data sets}

For the GENAHTO Project several other separately funded data sets from higher-income countries have been added to the WHO-TH data archive. These include national surveys in Denmark (2011), Scotland (2012), Switzerland (2012 and 2016), São Paulo, Brazil (2014-15), Ireland (2015), and the United States (the 2015 National Alcohol Survey and a parallel National Alcohol's Harms to Others Survey funded separately by NIAAA). These surveys are also archived at the La Trobe University CAPR, although they have not yet been analyzed together with the WHO-TH surveys. Taken together, these surveys provide extensive data on harms due to others' drinking from the victim's perspective.

\section{The GENAHTO Project}

\section{Project personnel and meetings}

In 2014-15 GENACIS members Kim Bloomfield, Jason Bond, Tom Greenfield, Robin Room, Richard Wilsnack, and Sharon Wilsnack wrote the grant application for what is now the multinational study of alcohol's harms to others, funded by NIAAA, part of the U.S. National Institutes of Health, in March 2016. The grant is based at the Public Health Institute's Alcohol Research Group (ARG) and has three Multiple Principal Investigators: Tom Greenfield (at ARG, contact Multiple Principal Investigator), Sharon Wilsnack (University of North Dakota School of Medicine and Health 
Sciences), and Kim Bloomfield (Aarhus University Centre for Alcohol and Drug Research, Copenhagen, Denmark). Co-investigators of the grant are based at ARG (Kathryn Karriker-Jaffe), University of North Dakota (Richard Wilsnack), the Centre for Addiction and Mental Health in London, Ontario (Kathryn Graham), the Addiction Switzerland Research Institute (Gerhard Gmel), and the La Trobe University CAPR (Robin Room, Anne-Marie Laslett, and Sandra Kuntsche). Other key personnel include biostatisticians Ulrike Grittner (CharitéUniversitätsmedizin Berlin) and Libo Li (ARG). The project also has consultants representing major world regions: Vivek Benegal (Asia), Florence Kerr-Corrêa (Latin America), Isidore Obot (Africa), and Orratai Waleewong (Asia).

At their organizational meeting preceding the 2016 Kettil Bruun Society Symposium in Stockholm, grant personnel selected a project name: GENAHTO, an acronym for Gender and Alcohol's Harm to Others. "GEN" signifies the importance of gender in the study of AHTO, as well as the project's continuity with the GENACIS Project. Key personnel of the GENAHTO Project meet twice a year, and the three Multiple Principal Investigators hold Skype meetings at least monthly.

\section{Conceptual model}

GENAHTO analyses are guided by several theoretical perspectives, including (1) the socioecological framework (Bronfenbrenner, 1989; Perry, Baranowski, \& Parcel, 1990), emphasizing how AHTO occurs in a multilevel context with nested factors interacting to influence these harms; (2) Krieger's ecosocial perspective (Krieger, 2001, 2011), explicating how macrosocial factors can affect harm done by drinkers; (3) Hobfoll's conservation of resources theory (Hobfoll, 2001), identifying how loss/lack of social resources can affect vulnerability to harm from drinkers; and (4) resilience theory (Godette, Headen, \& Ford, 2006; Widom, Czaja, Wilson, Allwood, \& Chauhan, 2012), emphasizing how close social ties can mitigate harm from others' drinking.

\section{Figure 1}

\section{A conceptual model of multilevel influences on alcohol's harm to others}

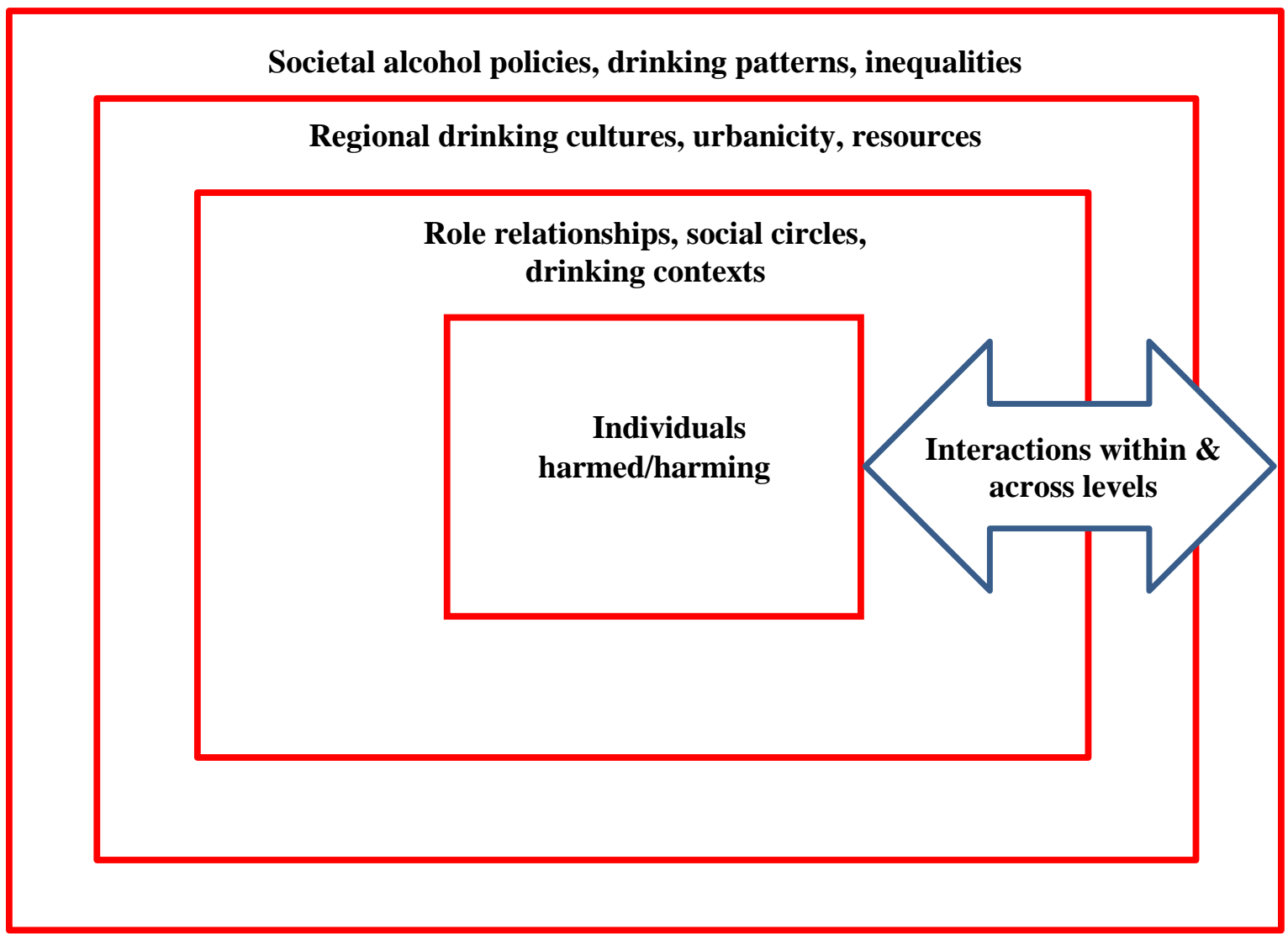

No single theory can yet explain and predict alcohol's harms to others, and no single theory is comprehensive enough to encompass all of the hypotheses and analyses proposed by the GENAHTO Project. However, multiple theoretical perspectives have helped us construct a conceptual model in which AHTO occurs within a nested multilevel set of potential influences (see Figure 1). This model allows a more complex and realistic view of alcohol problems than has 
been possible in much of the earlier research. Central are the characteristics of individuals experiencing and causing AHTO, such as gender and drinking patterns. These are imbedded in the individual's role relationships (such as in families and friendships), social circles (such as exposure to heavier drinkers), and drinking contexts (such as in public places or at home), which in turn are imbedded in regions where the individual lives (with characteristics such as urbanicity, local resources, and drinking cultures, including gender-specific rates of abstention and heavy episodic drinking, and gender-differentiated drinking norms). The highest level of potential influences are societal characteristics, including especially national alcohol policies, but also social disparities, such as gender inequality and income inequality. Each level of impacting factors may be associated with AHTO directly (i.e., with additive effects) but also in interaction with lower- and higher-level characteristics (multiplicative or contingent effects). Multilevel modeling is used also to examine how regional factors may moderate the associations between the societal variables and AHTO, controlling for individual characteristics.

\section{Major aims of GENAHTO Project}

Aim 1: Identify characteristics of individual victims of AHTO and individual drinkers who cause AHTO. We examine both individual and social/contextual characteristics that make a person more likely to (a) experience and (b) cause AHTO. As one example, we investigate whether women evidence more family/relationship and financial harms, whereas men show more harms involving strangers, in part because of greater heavy and public drinking by men. Multilevel analyses examine, for example, whether the prevalence of AHTO is higher in regions and countries with a high Detrimental Drinking Pattern score (Gmel, Room, Kuendig, \& Kuntsche, 2007).

Aim 2: Determine how rates of AHTO differ among regions within countries. We seek to learn whether differences in regional rates of AHTO (experienced and caused) within countries indicate that alcohol problem rates can no longer be adequately evaluated as national averages (Grittner et al., 2018; Wilsnack et al., in press). We also assess possible reasons for higher regional rates of AHTO, including urbanicity, socioeconomic disadvantage, and genderspecific drinking patterns (e.g., where high rates of abstention among women combine with high rates of heavy drinking among men). Particular attention is paid to regional differences in drinking cultures (e.g., measured by injunctive norms for perceived acceptable/unacceptable levels of drinking), and how these may affect rates of AHTO (e.g., where intoxication is widely acceptable). Multilevel analyses will help reveal to what extent regional characteristics are associated with AHTO beyond what individual and country characteristics can tell us.

Aim 3: Assess how national alcohol policies and societal factors are associated with individual and regional levels of AHTO. A major aspect of this aim is to identify factors that modify associations of national alcohol policies with AHTO.
As examples, we want to learn whether regional drinking cultures that favor heavy drinking and intoxication alter how particular alcohol policies, such as restrictions on availability, are associated with individual and regional ATHO. We seek to disentangle societal patterns of alcohol consumption and other societal factors (e.g., gender inequality, income inequality) from policy variables, and to learn how effects of each on AHTO may be moderated by regional conditions.

\section{Study Design and Methods}

\section{Major Data Sets and Their Uses}

The GENAHTO Project uses 21 of the earlier GENACIS surveys. As noted above, the GENACIS surveys include a number of questions for drinkers about harms they inflicted on someone else (e.g., alcohol-related harms to family finances, disruption of an intimate relationship, aggression toward a spouse or partner), allowing us to examine AHTO from the harming drinker's perspective. These surveys include regional (subnational) indicators (e.g., states in federal countries, provinces, counties, postal codes, or other administrative districts), allowing multilevel analyses by region within country.

The 17 more recent AHTO surveys, including the separately funded surveys in Denmark, Ireland, Scotland, Sweden, Switzerland, and the United States, have all asked about alcohol-related harm from the victim's perspective. These surveys contain 13-18 items on alcohol's harms as experienced by those being harmed. In addition to variables measuring alcohol's harm to others, the AHTO surveys also contain assessments of the respondent's own alcohol use patterns and other items. Like the 21 chosen GENACIS surveys, these AHTO surveys have regional indicators, permitting refined contextual analyses.

Table 1 shows characteristics of 21 surveys from the GENACIS Project and 17 surveys focused on AHTO. The sampling frame column in Table 1 indicates which surveys had nationally representative samples and which had regional samples. The main reasons for using regional, rather than national, samples were cost and/or politics. For example, the GENACIS and the AHTO surveys in Nigeria and the GENACIS survey in Sri Lanka avoided regions where civil strife and violence made the security situation unfavorable for conducting surveys (Hettige \& Paranagama, 2005; Ibanga, Adetula, Dagona, Karick, \& Ojiji, 2005). Where it was necessary to conduct surveys with regional sampling frames, study directors were expected to select regions that (1) were as representative as possible of national characteristics of their country; (2) included both rural and urban areas; (3) corresponded to a governmental unit(s) that could provide aggregate statistics for cultural-level analyses; and (4) included a population with varied drinking patterns (e.g., rather than a region of abstainers only) (Laslett, Room, Waleewong, Stanesby, \& Callinan, in press; Wilsnack et al., 2009; Wilsnack, Kristjanson, Benson, \& Wilsnack, 2012). 
Table 1

Characteristics of GENACIS and AHTO Surveys Used in GENAHTO Project

\begin{tabular}{|c|c|c|c|c|c|c|c|c|c|}
\hline \multicolumn{10}{|c|}{ GENDER, ALCOHOL AND CULTURE: AN INTERNATIONAL STUDY (GENACIS) SURVEYS } \\
\hline Country & $\begin{array}{c}\text { Survey } \\
\text { Year }\end{array}$ & $\begin{array}{c}\text { Age } \\
\text { Range }\end{array}$ & $\begin{array}{c}\text { Sampling } \\
\text { Frame }\end{array}$ & $\begin{array}{c}N \\
\text { Regions }\end{array}$ & $\begin{array}{c}\text { Response } \\
\text { Rate }\end{array}$ & $\begin{array}{c}\text { Administration } \\
\text { Mode }\end{array}$ & Total $N$ & Men $n$ & $\begin{array}{c}\text { Women } \\
n\end{array}$ \\
\hline Australia I & 2007 & $18+$ & Regional & $2^{1}$ & $38 \%$ & Telephone & 2434 & 1000 & 1434 \\
\hline Belize & 2005 & $18+$ & National & $6^{2}$ & $83 \%$ & Face-to-face & 3973 & 1903 & 2070 \\
\hline Canada & 2004 & $18-75$ & National & $5^{3}$ & unknown & Telephone & 13,812 & 5940 & 7872 \\
\hline Costa Rica & 2003 & $18+$ & Regional & $4^{4}$ & $58 \%$ & Face-to-face & 1273 & 416 & 857 \\
\hline Czech Republic & 2002 & $18-64$ & National & $2^{5}$ & $73 \%$ & Face-to-face & 2526 & 1244 & 1282 \\
\hline Denmark I & 2003 & $15+$ & National & $5^{6}$ & $40 \%$ & Telephone & 2030 & 897 & 1133 \\
\hline Finland & 2000 & $16-70$ & National & $5^{7}$ & $79 \%$ & Face-to-face & 1932 & 945 & 987 \\
\hline Germany & 2000 & $18-60$ & National & $8^{8}$ & $51 \%$ & Postal & 8119 & 3676 & 4443 \\
\hline India I & 2003 & $16+$ & Regional & $4^{9}$ & unknown & Face-to-face & 2597 & 1347 & 1250 \\
\hline Ireland I & 2002 & $18+$ & National & $4^{10}$ & $70 \%$ & Face-to-face & 1047 & 508 & 539 \\
\hline Mexico & 1998 & $18-65$ & National & $6^{11}$ & $88 \%$ & Face-to-face & 5711 & 2382 & 3329 \\
\hline New Zealand I & 2007 & $18-70$ & National & $5^{12}$ & $50 \%$ & Postal & 1875 & 820 & 1055 \\
\hline Nicaragua & 2005 & $15+$ & Regional & $5^{13}$ & unknown & Face-to-face & 2030 & 614 & 1416 \\
\hline Nigeria I & 2003 & $18+$ & Regional & $6^{14}$ & unknown & Face-to-face & 2064 & 1109 & 955 \\
\hline Peru & 2005 & $18-65$ & Regional & $2^{15}$ & unknown & Face-to-face & 1531 & 516 & 1015 \\
\hline Spain & 2002 & $18+$ & Regional & $8^{16}$ & unknown & Face-to-face & 1850 & 894 & 956 \\
\hline Sri Lanka I & 2002 & $18+$ & Regional & $7^{17}$ & unknown & Face-to-face & 1193 & 603 & 590 \\
\hline Sweden I & 2002 & $17+$ & National & $7^{18}$ & $68 \%$ & Telephone & 5472 & 2656 & 2816 \\
\hline Switzerland I & 1997 & $15+$ & National & $7^{19}$ & $68 \%$ & Telephone & 12,994 & 5755 & 7239 \\
\hline Uganda & 2003 & $18+$ & Regional & $4^{20}$ & $84 \%$ & Face-to-face & 1478 & 720 & 758 \\
\hline USA I & 2000 & $18+$ & National & $9^{21}$ & $58 \%$ & Telephone & 7497 & 3444 & 4053 \\
\hline \multicolumn{10}{|c|}{ ALCOHOL'S HARMS TO OTHERS (AHTO) SURVEYS } \\
\hline Country & $\begin{array}{c}\text { Survey } \\
\text { Year }\end{array}$ & $\begin{array}{c}\text { Age } \\
\text { Range }\end{array}$ & $\begin{array}{c}\text { Sampling } \\
\text { Frame }\end{array}$ & $\begin{array}{c}N \\
\text { Regions }\end{array}$ & $\begin{array}{c}\text { Response } \\
\text { Rate }\end{array}$ & $\begin{array}{c}\text { Administration } \\
\text { Mode }\end{array}$ & Total $N$ & Men $n$ & $\begin{array}{c}\text { Women } \\
n\end{array}$ \\
\hline Australia II & 2008 & $18+$ & National & $5^{22}$ & $35 \%$ & Telephone & 2649 & 1089 & 1560 \\
\hline Brazil & $2014-15$ & $18-59$ & Regional $^{\mathrm{a}}$ & $5^{23}$ & $59 \%$ & Face-to-face & 1083 & 474 & 609 \\
\hline Chile & $2012-13$ & $18+$ & Regional & $5^{24}$ & $72 \%$ & Face-to-face & 1500 & 697 & 803 \\
\hline Denmark II & 2011 & $15-79$ & National & $5^{25}$ & $64 \%$ & Web/Telephone & 5133 & 2423 & 2710 \\
\hline India II & 2013-14 & $18+$ & Regional & $4^{26}$ & $97 \%$ & Face-to-face & 3403 & 1623 & 1780 \\
\hline Ireland II & 2010 & $18+$ & National & $4^{27}$ & unknown $^{\mathrm{b}}$ & Face-to-face & 1008 & 492 & 516 \\
\hline Ireland III & 2015 & $18+$ & National & $4^{27}$ & $37 \%$ & Telephone & 2005 & 999 & 1006 \\
\hline Lao PDR & 2013 & $15-64$ & National & $3^{28}$ & $99 \%$ & Face-to-face & 1257 & 519 & 738 \\
\hline New Zealand II & $2008-09$ & $12-80$ & National & $5^{29}$ & $64 \%$ & Telephone & 3068 & 1232 & 1836 \\
\hline Nigeria II & $2012-13$ & $18+$ & Regional & $3^{30}$ & unknown $^{\mathrm{c}}$ & Face-to-face & 2270 & 1390 & 880 \\
\hline Scotland & 2012 & $16+$ & National & $8^{31}$ & unknown $^{\mathrm{b}}$ & Face-to-face & 1007 & 456 & 551 \\
\hline Sri Lanka II & 2013-14 & $18+$ & National & $6^{32}$ & $93 \%$ & Face-to-face & 2475 & 1214 & 1261 \\
\hline Sweden II & 2013 & $17-84$ & National & $7^{33}$ & $59 \%$ & Postal \& Web & 15,576 & 7189 & 8387 \\
\hline Switzerland II/ III ${ }^{\mathrm{d}}$ & $2012-2016$ & $15+$ & National & $7^{34}$ & $51 \% / 45 \%$ & Telephone & 4892 & 2227 & 2665 \\
\hline Thailand & $2012-13$ & $18-70$ & National & $6^{35}$ & $94 \%$ & Face-to-face & 1695 & 694 & 1001 \\
\hline USA II & $2014-2015$ & $18+$ & National $^{\mathrm{e}}$ & $9^{36}$ & $60 \%{ }^{\mathrm{f}}$ & Telephone & 8608 & 3506 & 5102 \\
\hline Vietnam & $2012-13$ & $18-84$ & National & $6^{37}$ & $99 \%$ & Face-to-face & 1501 & 753 & 748 \\
\hline
\end{tabular}


${ }^{a}$ Sao Paulo City only.

${ }^{\mathrm{b}}$ National quota sample.

${ }^{c}$ A response rate of $99 \%$ was reported among households where someone was home.

${ }^{\mathrm{d}}$ Harms questions were asked in the 2012 and 2016 national surveys; cases from both studies were combined to provide data for these analyses.

${ }^{\mathrm{e}}$ Combines harms items from the 2015 National Alcohol Survey $(\mathrm{N}=5919)$ and a parallel, separately funded National Alcohol's Harms to Others Survey (NAHTOS; $\mathrm{N}=2689$ ).

${ }^{\mathrm{f}}$ Cooperation rate (NAHTOS only).

${ }^{1}$ State of Victoria: Melbourne (including suburbs near Melbourne), other regions of Victoria (not Melbourne).

${ }^{2}$ Corozal, Orange Walk, Belize City, Cayo, Stann Creek, Toledo.

${ }^{3}$ Atlantic Provinces (Newfoundland, Prince Edward Island, Nova Scotia, New Brunswick), Quebec, Ontario, Prairie Provinces

(Manitoba, Saskatchewan, Alberta), British Columbia.

${ }^{4}$ San José, Alajuela, Cartago, Heredia.

${ }^{5}$ Bohemia, Moravia.

${ }^{6}$ Hovedstaden (Capital Region), Sjaelland (Zealand), Syddanmark (Southern Denmark), Midtjilylland (Central Denmark),

Nordjylland (Northern Denmark).

${ }^{7}$ Uusimaa, Southern Finland, Eastern Finland, Western Finland, Northern Finland.

${ }^{8}$ Schleswig-Holstein, Hamburg; Lower Saxony, Bremen; North Rhine-Westphalia; Hesse, Rhineland-Palatinate, Saarland;

Baden-Württemberg; Bavaria; Berlin, Brandenburg, Mecklenburg-Western Pomerania; Saxony, Saxony-Anhalt, Thuringia.

${ }^{9}$ Karnataka State: Bangalore, Bangalore rural, Bagalore urban; Bidar; Dakshina Kannada; Davanagere, Davanagere urban.

${ }^{10}$ Dublin, Rest of Leinster, Munster, Connaught /Ulster.

${ }^{11}$ Baja California, Baja California Sur; Chihuahua, Durango, Sonora, Sinaloa; Coahuila, Nuevo Leon, Tamaulipas; Jalisco,

Michoacan, Guanajuato, San Luis Potosí; Distrito Federal, Estado de Mexico, Morelos, Puebla, Hidalgo; Veracruz, Chiapas,

Tabasco, Yucatan

${ }^{12}$ Upper North Island, Mid North Island, Lower North Island, Upper South Island, Lower South Island.

${ }^{13}$ Estelí (north), Juigalpa (east), Rivas (south), León (west), Bluefields (Atlantic coast).

${ }^{14}$ Benue (north), Federal Capital Territory (north), Nasarawa (north), Plateau (north), Akwa Ibom (south), Rivers (south).

${ }^{15}$ Lima, Ayacucho.

${ }^{16}$ Cantabria, Alicante, Castellon, Valencia, La Coruña, Lugo, Orense, Pontevedra.

${ }^{17}$ North Western Province, North Central Province, Central Province, Uva, Southern Province, Sabaragamuwa, Western Province.

${ }^{18}$ Kronoberg, Blekinge, Halland; Norrland; Other Götaland (not Western Götaland); Other Svealand (not Stockholm); Skåne; Greater Stockholm; Western Götaland.

${ }^{19}$ Area around Lake Geneva, Swiss Plateau, Northwestern Switzerland, Zurich, Eastern Switzerland, Central Switzerland, Tessin.

${ }^{20}$ Wakiso (central), Kabale (west), Tororo (east), Lira (north).

${ }^{21}$ New England, Mid Atlantic, Northeast Central, Northwest Central, South Atlantic, Southeast Central, Southwest Central, Mountain, Pacific.

${ }^{22}$ New South Wales and Australian Capital Territory; Victoria and Tasmania; Queensland; South Australia; Western Australia and Northern Territory.

${ }^{23}$ Districts of São Paulo city divided into five groups North São Paulo, South São Paulo, East São Paulo, West São Paulo, Center São Paulo.

${ }^{24}$ Seven cities and surrounding areas, located in five regions: Northern Chile (Northern tip), North Central Valley, Central, South Central Valley, Southern Chile (Southern tip).

${ }^{25}$ Hovedstaden (Capital Region of Denmark), Sjaelland (Zealand), Syddanmark (Southern Denmark), Midtjylland

(Central Denmark), Nordjylland (Northern Denmark).

${ }^{26}$ Karnataka State: Bangalore, Kolar, Hubli, Manipal.

${ }^{27}$ Dublin, Rest of Leinster, Munster, Connaught/Ulster.

${ }^{28}$ Vientiane Capital, Luangprabang, Champasack.

${ }^{29}$ Upper North Island, Mid-North Island, Lower North Island, Upper South Island, Lower South Island.

${ }^{30}$ Benue (north), Akwa Ibom (south), Rivers (south)

${ }^{31}$ Highlands and Islands, North East Scotland, Mid Scotland \& Fife, Lothian (Lothians), Central Scotland, Glasgow, West Scotland, South Scotland.

${ }^{32}$ Western region (most urbanized); largely plantation districts; Southern province (mostly Sinhalese); Northeast region (largely minorities); mostly rural region; largely plantation region, but also rural.

${ }^{33}$ Kronoberg, Blekinge, Halland; Norrland; Other Gőtaland (not Western Gőtaland); Other Svealand (not Stockholm); Skåne; Greater Stockholm; Western Götaland.

${ }^{34}$ Area around Lake Geneva, Swiss Plateau, Northwestern Switzerland, Zurich, Eastern Switzerland, Central Switzerland, Tessin.

${ }^{35}$ Chonburi, Surat Thani, Chiang Mai, Khon Kaen, Bangkok, Other Provinces (specific locales).

${ }^{36}$ New England, Mid Atlantic, Northeast Central, Northwest Central, South Atlantic, Southeast Central, Southwest Central, Mountain, Pacific.

${ }^{37}$ Dak Lak Province, Khanh Hoa Province, Long An Province, Dong Nai Province, Lai Chau Province, Vinh Phuc Province. 


\section{Measures}

Individual-level measures for the WHO-TH surveys (Callinan et al., 2016) and the GENACIS surveys (Wilsnack et al., 2009) have been described in detail elsewhere. Nonetheless, a few examples are given here.

Drinking-related questions in the GENACIS surveys obtained information about drinking patterns as well as the total volume of alcohol consumed. The surveys included questions about the generic frequency and quantity per drinking day (combining all types of alcoholic beverages), beverage-specific frequency and quantity (asked separately for wine, beer, and liquor), and consumption of locally produced or culturally unique beverages. The GENACIS questionnaire contained a reference chart for estimating average sizes of "drinks" of each type of alcoholic beverage and for converting drinks into grams of absolute alcohol (ethanol). Drinking-related questions in most AHTO surveys were less detailed than in the GENACIS surveys. However, it is usually possible to characterize the generic quantity and frequency of alcohol consumption of the respondent and the generic quantity and frequency of heavy and intoxicated drinking of the person designated as the "most harmful heavy drinker" in the respondent's life.

As noted earlier, both the GENACIS surveys and the AHTO surveys have questions about alcohol-related harms. Most of the GENACIS surveys have eight or more questions about alcohol-related harms that the respondent's own drinking has inflicted on others. These questions ask about such problems as getting into a fight because of one's drinking, losing a friendship or other close relationship, or having financial problems. The eight common AHTO included in the GENACIS surveys are listed in an early GENAHTO paper (Wilsnack et al., in press).

The 17 AHTO surveys contain 13 to 18 items on alcohol's harms as experienced by those being harmed. These items range from harm committed by strangers (e.g., being threatened or yelled at by a drunken stranger; being kept awake at night by noise from drunken people) to being harmed (e.g., physical abuse, sexual abuse, neglect) by a known household or family member. The 13 questions in the "Brief Assessment of Harms" are listed on the GENAHTO website (www.genahto.org).

Many regional-level variables (e.g., education, income, urbanicity, gender inequality, income/educational inequality) are aggregated from responses of survey participants in each region. Regional- and societal-level drinking culture variables can also be aggregated from key individual-level alcohol variables, including 12-month abstention, frequency of drinking days, quantity (standard drinks consumed) per drinking day, maximum drinks consumed, and injunctive drinking norms. Some societallevel measures are available from archival sources-for example, gender inequality (Dijkstra \& Hanmer, 2000; Hausmann, Tyson, \& Zahidi, 2007; Permanyer, 2013; Schwab et al., 2017) and income inequality (World Bank, 2017).
Information on alcohol policies for each country are obtained from WHO Global Status Reports (WHO, 2011, 2014) and the WHO Global Information System on Alcohol and Health (GISAH) (WHO, 2013), using alcohol policies in effect the year prior to each survey, updated where necessary by country study directors. For the United States we use NIAAA's Alcohol Policy Information System (NIAAA, 2008). Our policy classification, guided by three cross-national policy studies (Brand, Saisana, Rynn, Pennoni, \& Lowenfels, 2007; Cook, Bond, \& Greenfield, 2014; Paschall, Grube, \& Kypri, 2009), emphasizes four alcohol policy domains: physical availability, prices, advertising, and motor vehicle operation. In countries where there is internal variation in alcohol policies, policies may need to be studied at both subnational and national levels.

The WHO GISAH has several limitations. For example, a number of variables are either binary (e.g., alcohol excise taxes) or inadequately measured (e.g., pricing). Better price data from the World Bank and from the ATLAS on Resources for the Prevention and Treatment of Substance Use Disorders (WHO, 2010) may help in calculating affordability indices, following methods by Brand et al. (2007). There will remain uncertainty regarding enforcement of alcohol policies, but GISAH data have shown promise in multinational studies predicting several outcomes (e.g., Cook et al., 2014; Paschal et al., 2009).

\section{Data Analysis Methods}

One major data analysis method used in GENAHTO is multilevel modeling (Raudenbush \& Bryk, 2002)—for example, to examine variability in individual (level-1) relationships across characteristics of countries and regions in three-level models. Random effects for both region and country in the same model (i.e., three-level models) can be used to determine how much of the variation in AHTO is related to differences between countries versus differences between regions.

A second major analytic method used in the GENAHTO Project is propensity score (PS) methods (Rosenbaum \& Rubin, 1984; Rubin, 1997). For example, when evaluating how AHTO predicts victims' health outcomes, PS methods can balance effects of confounding variables (e.g., age, education, urbanicity) on harmed versus not harmed groups. Although limited to simple cross-group comparisons, PS matching can allow clearer inferences about effects of AHTO than would be provided by standard regression approaches. PS analyses will be the main analytic technique when outcome differences between two well-defined groups (e.g., harmed vs. non-harmed individuals) are of primary interest (Karriker-Jaffe, Li, \& Greenfield, 2018). Multilevel models will be used when estimation of effects of multiple variables (including confounders) are of interest.

\section{Ethical Review}

Each country survey was reviewed according to the ethical principles and methods that apply to research participants in that country. The overall GENACIS Project was approved by the Institutional Review Board of the University of North Dakota. The WHO-TH Project was approved by the WHO 
Ethics Review Committee, and the overall GENAHTO Project was approved by the Institutional Review Board of the Public Health Institute.

\section{Future Directions and Public Health Implications}

\section{Additional Countries}

Several additional countries have asked the GENAHTO Project for guidance and support in conducting AHTO surveys. For example, a research group in Ukraine has received funding to interview family members of persons in treatment for alcohol use disorders, to learn about harms family members have experienced from the treated individual's drinking. The Ukraine group also hopes to interview a representative general population sample, which could be part of collaborative analyses of the GENAHTO Project. As other researchers and policy makers increasingly recognize the important costs of heavy drinking for people other than the drinkers, we hope that more countries will decide to conduct AHTO surveys of their own populations. We encourage those countries to use definitions and measures that are comparable to those in the GENAHTO Project (e.g., to include as a minimum the 13-item "Brief Assessment of Harms" mentioned above).

\section{Longitudinal Research}

Current surveys of the GENAHTO Project are crosssectional, limiting inferences about temporal-causal relationships among variables. We hope that the crosssectional analyses of the GENAHTO Project will suggest fruitful directions for future longitudinal research that can clarify time-ordered patterns and causal associations of alcohol's harms to others.

\section{Potential Implications for Surveillance}

It has become clear that surveys monitoring trends in alcohol consumption and effects of alcohol policies need to ask about harmful consequences of alcohol consumption not just for the drinker, but also for persons other than the drinker. As noted earlier, studies attempting to estimate the financial costs of AHTO (e.g., Laslett et al., 2010) have found that including alcohol's harms both to the drinker and to other persons may greatly increase (perhaps even twofold) the estimated societal costs of heavy alcohol consumption.

Effective (and cost-effective) international monitoring of public health risks depends on use of consistent measurement in multiple countries and regions (e.g., Moskalewicz, Room, \& Thom, 2016). Ideally the GENAHTO Project could identify and disseminate the most useful questions to ask about AHTO in diverse societies and cultures. GENAHTO investigators are currently trying to assess the perceived severity of various alcohol-related harms to learn whether there are specific AHTO that are consistently perceived as "severe/very harmful" or as "mild/not very harmful." GENAHTO findings to date indicate considerable variation across countries and regions within countries (and probably across various drinking contexts), in the prevalence of specific harms and also in how severe given harms are perceived to be. Ultimately, an important contribution of the GENAHTO Project to international surveillance efforts may be to determine to what extent commonly used harm questions have similar versus different meanings in different cultural contexts, and to clarify the questions that should be asked to ensure that harmful consequences of others' drinking are appropriately and accurately assessed.

\section{Implications for Intervention and Policy}

A long-term goal of the GENAHTO Project is to inform prevention and intervention planning and alcohol policy development. Increased understanding of individual and social characteristics of both perpetrators and victims of AHTO may help identify high-risk groups as targets for prevention and intervention. An urgent need exists for evidence-based evaluation of alternative intervention strategies for the high-risk groups thus identified. A recent expert panel (Karriker-Jaffe, Room, Giesbrecht, \& Greenfield, 2018) advocates a public health approach that "gives preference to interventions that not only are broadly effective but also minimize social labeling and stigmatization" of individual heavy or problem drinkers ( $p$. 241).

A recent study based on emergency-room data in 28 countries found that higher scores on an index of alcohol policy variables drawn from GISAH in four policy domains were associated with fewer alcohol-related injuries (Cherpitel et al., in press). Domains in the index included (1) physical availability of alcoholic beverages (such regulations as legal minimum drinking age, government retail monopoly, restrictions on outlet density, and limits on hours and days of sale); (2) vehicular policies (e.g., random breath testing, legal BAC limits, and related penalties); (3) advertising and promotion regulations; and (4) drinking context-related programs (such as community mobilization and training in responsible beverage service). GENAHTO research may help reveal how such alcohol policy domains are associated with levels of harms from others' drinking, thereby providing evidence to inform alcohol policymaking. Furthermore, better identification of regional characteristics and their association with the effectiveness of specific alcohol policies may help to identify optimal "matches" of alcohol policies and regional characteristics.

Finally, it is good that we now recognize the much higher societal cost of alcohol-related problems when harms that drinking causes to other people are added to the harms to the drinker. We hope that this recognition will increase efforts to prevent and reduce the multiple harms caused by heavy and harmful use of alcohol.

\section{Acknowledgments}

This paper is from the GENAHTO Project (Gender and Alcohol's Harm to Others), supported by NIAAA Grant No. R01 AA023870 (Alcohol's Harm to Others: Multinational Cultural Contexts and Policy Implications; Multiple 
Principal Investigators: T. Greenfield, S. Wilsnack, K. Bloomfield). GENAHTO is a collaborative international project affiliated with the Kettil Bruun Society for Social and Epidemiological Research on Alcohol and coordinated by research partners from the Alcohol Research Group/Public Health Institute (USA), University of North Dakota (USA), Aarhus University (Denmark), the Centre for Addiction and Mental Health (Canada), the Centre for Alcohol Policy Research at La Trobe University (Australia), and the Addiction Switzerland Research Institute (Switzerland). Support for aspects of the project has come from the World Health Organization, the European Commission (Concerted Action QLG4-CT-20010196), the Pan American Health Organization, the Thai Health Promotion Foundation, the Australian National Health and Medical Research Council (Grant No. 1065610), and the U.S. National Institute on Alcohol Abuse and Alcoholism/National Institutes of Health (Grants R21 AA012941， R01 AA015775, R01 AA022791, R01 AA023870, and P50 AA005595). Support for individual country surveys was provided by government agencies and other national sources. National funds also contributed to collection of all of the data sets included in WHO projects.

The authors are grateful to Ulrike Grittner, Perry Benson, Arlinda Kristjanson, and Oliver Stanesby for their assistance in preparing the survey characteristics table; and to Richard Wilsnack for helpful comments on an earlier version of this paper.

\section{References}

Berning, A., Compton, R., \& Wochinger, K. (2015). Results of the 2013-2014 National Roadside Survey of Alcohol and Drug Use by Drivers. (Traffic Safety Facts Research Note. Report No. DOT HS 812 118). Washington, DC: National Highway Traffic Safety Administration.

Brand, D. A., Saisana, M., Rynn, L. A., Pennoni, F., \& Lowenfels, A. B. (2007). Comparative analysis of alcohol control policies in 30 countries. PLoS Medicine, 4(4), e151.

Bronfenbrenner, U. (1989). Ecological systems theory. In R. Vasta (Ed.), Annals of child development (pp. 187249). Greenwich, CT: JAI Press.

Callinan, S., Laslett, A.-M., Rekve, D., Room, R., Waleewong, O., Benegal, V., . . \& \& Thamarangsi, T. (2016). Alcohol's harms to others: An international collaborative project. International Journal of Alcohol and Drug Research, 5(2), 25-32.

Casswell, S., Harding, J. F., You, R. Q., \& Huckle, T. (2011). Alcohol's harm to others: Self-reports from a representative sample of New Zealanders. The New Zealand Medical Journal, 124(1336), 75-84.

Cherpitel, C. J., Witbrodt, J., Korcha, R. A., Ye, Y., Kool, B., \& Monteiro, M. (in press). Multi-level analysis of alcohol-related injury, societal drinking pattern and alcohol control policy: Emergency department data from 28 countries. Addiction.

Cook, W. K., Bond, J., \& Greenfield, T. K. (2014). Are alcohol policies associated with alcohol consumption in low- and middle-income countries? Addiction, 109(7), 1081-1090.

Dijkstra, A. G., \& Hanmer, L. C. (2000). Measuring socioeconomic GENDER inequality: Toward an alternative to the UNDP Gender-Related Development Index. Feminist Economics, 6(2), 41-75.

Ferris, J. A., Laslett, A.-M., Livingston, M., Room, R., \& Wilkinson, C. (2011). The impacts of others' drinking on mental health. Medical Journal of Australia, 195(3), S22-S26.

Fillmore, K. M. (1985). The social victims of drinking. British Journal of Addiction, 80(3), 307-314.

Flynn, A., \& Graham, K. (2010). "Why did it happen?": A review and conceptual framework for research on perpetrators' and victims' explanations for intimate partner violence. Aggression and Violent Behavior, 15(3), 239-251.

Giesbrecht, N., Cukier, S., \& Steeves, D. (2010). [Editorial] Collateral damage from alcohol: Implications of 'second-hand effects of drinking' for populations and health priorities. Addiction, 105(8), 1323-1325.

Gmel, G., Room, R., Kuendig, H., \& Kuntsche, S. (2007). Detrimental drinking patterns: Empirical validation of the pattern values score of the Global Burden of Disease 2000 study in 13 countries. Journal of Substance Use, 12(5), 337-358.

Godette, D. C., Headen, S., \& Ford, C. L. (2006). Windows of opportunity: Fundamental concepts for understanding alcohol-related disparities experienced by young blacks in the United States. Prevention Science, 7(4), 377-387.

Graham, K., Bernards, S., Munné, M., \& Wilsnack, S. C. (Eds.) (2008). Unhappy hours: Alcohol and partner aggression in the Americas. Washington, DC: Pan American Health Organization.

Greenfield, T. K., Karriker-Jaffe, K. J., Giesbrecht, N., Kerr, W. C., Ye, Y., \& Bond, J. (2014). Second-hand drinking may increase support for alcohol policies: New results from the 2010 National Alcohol Survey. Drug and Alcohol Review, 33(3), 259-267.

Greenfield, T. K., Karriker-Jaffe, K. J., Kaplan, L. M., Kerr, W.C., \& Wilsnack, S. C. (2015). Trends in and cooccurrence of family-related alcohol's harms to others: The four U.S. National Alcohol Surveys, 2000 to 2015. Substance Abuse: Research and Treatment, 9(S2), 1-9.

Greenfield, T. K., Ye, Y., Kerr, W. C., Bond, J., Rehm, J., \& Giesbrecht, N. (2009). Externalities from alcohol consumption in the 2005 US National Alcohol Survey: Implications for policy. International Journal of Environmental Research and Public Health, 6(12), 3205-3224.

Grittner, U., Wilsnack, S., Kuntsche, S., Greenfield, T. K., Wilsnack, R., Kristjanson, A., \& Bloomfield, K. (2018). Regional variations in harms due to strangers' drinking: Results from the new GENAHTO study. Paper presented at the $44^{\text {th }}$ Annual Alcohol Epidemiology Symposium of the Kettil Bruun Society, Chiang Mai, Thailand.

Hausmann, R., Tyson, L. D., \& Zahidi, S. (2007). The global gender gap report 2007. Geneva, Switzerland: World Economic Forum. 
Hettige, S., \& Paranagama, D. (2005). Gender, alcohol and culture in Sri Lanka. In I. S. Obot \& R. Room (Eds.), Alcohol, gender and drinking problems: Perspectives from low and middle income countries (pp. 167-188). Geneva, Switzerland: World Health Organization.

Hingson, R., \& Winter, M. (2003). Epidemiology and consequences of drinking and driving. Alcohol Research and Health, 27(1), 63-78.

Hobfoll, S. E. (2001). The influence of culture, community and the nested-self in the stress process: Advancing conservation of resources theory. Applied Psychology, 50(3), 337-421.

Hope, A. (2008). Alcohol-related harm in Ireland: A Health Service Executive report. Health Service ExecutiveAlcohol Implementation Group. Retrieved (July 26, 2012) from http://www.webcitation.org/69RrDx11G

Ibanga, A. J., Adetula, A. V., Dagona, Z., Karick, H., \& Ojiji, O. (2005). The contexts of alcohol consumption in Nigeria. In I. S. Obot \& R. Room (Eds.), Alcohol, gender and drinking problems: Perspectives from low and middle income countries (pp. 143-166). Geneva, Switzerland: World Health Organization.

Karriker-Jaffe, K. J., \& Greenfield, T. K. (2014). Gender differences in associations of neighbourhood disadvantage with alcohol's harms to others: A crosssectional study from the USA. Drug and Alcohol Review, 33(3), 296-303.

Karriker-Jaffe, K. J., Li, L., \& Greenfield, T. K. (2018). Estimating mental health impacts of alcohol's harms from other drinkers: Using propensity scoring methods with national cross-sectional data from the United States. Addiction. Advance online publication. doi:10.1111/add. 14283

Karriker-Jaffe, K. J., Room, R., Giesbrecht, N., \& Greenfield, T. K. (2018). Alcohol's harm to others: Opportunities and challenges in a public health framework. Journal of Studies on Alcohol and Drugs, 79, 239-243.

Kelley-Baker, T., Lacey, J. H., Voas, R. B., Romano, E., \& Yao, J. (2013). Drinking and driving in the United States: Comparing results from the 2007 and 1996 National Roadside Surveys. Traffic Injury Prevention, 14(2), 117-126.

Krieger, N. (2001). Theories for social epidemiology in the 21st century: An ecosocial perspective. International Journal of Epidemiology, 30(4), 668-677.

Krieger, N. (2011). Epidemiology and the people's health: Theory and context. New York, NY: Oxford University Press.

Laslett, A.-M., Catalano, P., Chikritzhs, T., Dale, C., Doran, C., Ferris, J., .. Wilkinson, C. (2010). The range and magnitude of alcohol's harm to others. Fitzroy, Victoria, Australia: AER Centre for Alcohol Policy Research, Turning Point Alcohol and Drug Centre.

Laslett, A.-M., Room, R., Ferris, J., Wilkinson, C., Livingston, M., \& Mugavin, J. (2011). Surveying the range and magnitude of alcohol's harm to others in Australia. Addiction, 106(9), 1603-1611.

Laslett, A.-M., Room, R., Waleewong, O., Stanesby, O., \& Callinan, S. (in press). Harm to others from drinking: Patterns in nine societies. Bangkok, Thailand: World Health Organization.
Lewis-Laietmark, C., Wettlaufer, A., Shield, K. D., Giesbrecht, N., April, N., Asbridge, M., . . . Stockwell, T. (2017). The effects of alcohol-related harms to others on self-perceived mental well-being in a Canadian sample. International Journal of Public Health, 62(6), 669-678.

Lund, I. O., Sundin, E., Konijnenberg, C., Rognmo, K., Martinez, P., \& Fielder, A. (2015). Harm to others from substance use and abuse. Substance Abuse: Research and Treatment, 9(S2), 119-124.

Moan, I. S., Storvoll, E. E., Sundin, E., Lund, I. O., Bloomfield, K., Hope, A., . . Kristjánsson, S. (2015). Experienced harm from other people's drinking: A comparison of Northern European countries. Substance Abuse: Research and Treatment, 9(S2), 45-57.

Moskalewicz, J., Room, R., \& Thom, B. (2016). Comparative monitoring of alcohol epidemiology across the EU: Baseline assessment and suggestions for future action. Synthesis report, 2017. Warsaw, Poland: PARPA (The State Agency for Prevention of Alcohol Related Problems).

Mugavin, J., Livingston, M., \& Laslett, A.-M. (2014). Seeking help because of others' drinking. Drug and Alcohol Review, 33(1), 161-168.

National Institute on Alcohol Abuse and Alcoholism. (2008). Alcohol Policy Information System. Bethesda, MD. Retrieved (May 21, 2014) from http://www.webcitation.org/6PkJSOfen

Paschall, M. J., Grube, J. W., \& Kypri, K. (2009). Alcohol control policies and alcohol consumption by youth: A multi-national study. Addiction, 104(11), 1849-1855.

Permanyer, I. (2013). A critical assessment of the UNDP's Gender Inequality Index. Feminist Economics, 19(2), $1-32$.

Perry, C. L., Baranowski, T., \& Parcel, G. S., (1990). How individuals, environments, and health behavior interact: Social learning theory. In K. Glanz, F. M. Lewis, \& B. K. Rimer (Eds.), Health behavior and health education: Theory, research and practice (pp. 161186). San Francisco, CA: Jossey-Bass.

Popova, S., \& Chambers, C. (Eds.). (2013). Special issue: Fetal alcohol spectrum disorders. The International Journal of Alcohol and Drug Research, 2(3), 1-92.

Popova, S., \& Chambers, C. (Eds.). (2014). Second special issue: Fetal alcohol spectrum disorders. International Journal of Alcohol and Drug Research, 3(1), 1-125.

Ramstedt, M., Sundin, E., Moan, I. S., Storvoll, E. E., Lund, I. O., Bloomfield, K., . . . Tigerstedt, C. (2015). Harm experienced from the heavy drinking of family and friends in the general population: A comparative study of six Northern European countries. Substance Abuse: Research and Treatment, 9(S2), 107-118.

Raudenbush, S. W., \& Bryk, A. S. (2002). Hierarchical linear models: Applications and data analysis methods (2nd ed.). Thousand Oaks, CA: SAGE Publications.

Raupach, T., Schäfer, K., Konstantinides, S., \& Andreas, S. (2006). Secondhand smoke as an acute threat for the cardiovascular system: A change in paradigm. European Heart Journal, 27(4), 386-392.

Rosenbaum, P. R., \& Rubin, D. B. (1984). Reducing bias in observational studies using subclassification on the 
propensity score. Journal of the American Statistical Association, 79(387), 516-524.

Rubin, D. B. (1997). Estimating causal effects from large data sets using propensity scores. Annals of Internal Medicine, 127(8), 757-763.

Saunders, J. B., Aasland, O. G., Babor, T. F., De la Fuente, J. R., \& Grant, M. (1993). Development of the Alcohol Use Disorders Identification Test (AUDIT): WHO collaborative project on early detection of persons with harmful alcohol consumption-II. Addiction, 88, 791804.

Schwab, K., Samans, R., Zahidi, S., Leopold, T. A., Ratcheva, V., Hausmann, R., \& Tyson, L. D. (2017). The global gender gap report 2017. Geneva, Switzerland: World Economic Forum.

Seid, A. K., Grittner, U., Greenfield, T. K., \& Bloomfield, K. (2015). To cause harm and to be harmed by others: New perspectives on alcohol's harms to others. Substance Abuse: Research and Treatment, 9(Suppl 2), 13-22.

U. S. Department of Health and Human Services. (2006). The health consequences of involuntary exposure to tobacco smoke: A report of the Surgeon General. Atlanta, GA: U. S. Department of Health and Human Services, Centers for Disease Control and Prevention, Coordinating Center for Health Promotion, National Center for Chronic Disease Prevention and Health Promotion, Office on Smoking and Health. Retrieved (March 28, 2012) from http://www.webcitation.org/66VO1tfz3

Widom, C. S., Czaja, S., Wilson, H. W., Allwood, M., \& Chauhan, P. (2012). Do the long-term consequences of neglect differ for children of different races and ethnic backgrounds? Child Maltreatment, 18(1), 52-55.

Wilsnack, R. W., Kristjanson, A. F., Wilsnack, S. C., Bloomfield, K., Grittner, U., \& Crosby, R. D. (in press). The harms that drinkers cause: Regional variations within countries. International Journal of Alcohol and Drug Research.
Wilsnack, R. W., Wilsnack, S. C., Kristjanson, A. F., Vogeltanz-Holm, N. D., \& Gmel, G. (2009). Gender and alcohol consumption: Patterns from the multinational GENACIS project. Addiction, 104(9), 1487-1500.

Wilsnack, S. C. (2012). The GENACIS Project: A review of findings and some implications for global needs in women-focused substance abuse prevention and intervention. Substance Abuse and Rehabilitation, 3(Suppl. 1), 5-15.

Wilsnack, S. C., Kristjanson, A. F., Benson, P. B., \& Wilsnack, R. W. (with the GENACIS R01 Consortium) (2012). Participation Guidelines. In Gender, Alcohol, and Culture: An International Study (GENACIS). Retrieved (July 27, 2018) from www.med.und.edu/genacis/

World Bank (2017). World Development Indicators: GINI index (World Bank estimate), 1990-2017. Retrieved from https://data.worldbank.org/indicator/SI.POV.GINI

World Health Organization. (2010). The ATLAS on substance use (2010): Resources for the prevention and treatment of substance use disorders. Geneva, Switzerland: WHO.

World Health Organization. (2011). Global status report on alcohol and health. Geneva, Switzerland: WHO. Retrieved (September 21, 2011) from http://www.webcitation.org/61rrYX4il

World Health Organization. (2012). Master research protocol. Harm to others from drinking: A WHO/Thai Health international collaborative research project. Geneva, Switzerland: WHO.

World Health Organization. (2013). Global Information System on Alcohol and Health (GISAH). Geneva, Switzerland: WHO. Retrieved (June 12, 2013) from http://www.webcitation.org/6HKT0zJGQ

World Health Organization (2014). Global status report on alcohol and health 2014. Geneva, Switzerland: WHO. 